\title{
MODIFIKASI PERKALIAN BERSUSUN UNTUK MENENTUKAN KOEFISIEN TRINOMIAL SERTA KONSTRUKSINYA PADA KERUCUT
}

\author{
Jufri $^{\mathrm{a}}$, M.D.H Gamal ${ }^{\mathrm{b}}$, Sri Gemawati ${ }^{\mathrm{c}}$ \\ ${ }^{\text {a }}$ Program Studi Teknik Informatika, FILKOM Universitas Pasir Pengaraian \\ Jl.Tuanku Tambusai, Kumu, Kab. Rokan Hulu, Riau, jufrirokan@ gmail.com \\ b, Program Studi Matematika, MIPA Universitas Riau \\ Kampus BinaWidya, Pekanbaru, mdhgamal@unri.ac.id \\ ${ }^{c,}$ Dosen Jurusan Matematika, MIPA Universitas Riau \\ Kampus BinaWidya, Pekanbaru, gemawati.sri@gmail.com
}

\begin{abstract}
ABSTRAK
Dalam berbagai literatur pada umumnya untuk menentukan koefisien trinomial dengan mudah dapat ditentukan dengan menggunakan konsep kombinasi dan koefisien binomial, hal ini disebabkan karena koefisien trinomial sangat erat hubungannya dengan koefisien binomial dan konsep kombinasi. Untuk konstruksi koefisien trinomial biasanya dikonstruksi pada limas Pascal yang asalnya adalah dari segitiga Pascal. Pada tulisan ini akan diberikan alternatif menentukan koefisien trinomial dan alternatif konstruksinya. Alternatif yang diberikan adalah dengan modifikasi perkalian bersusun. Modifikasi perkalian bersusun yang dimaksud adalah dengan hanya menuliskan bagian proses perkalian bersusun pada bentuk trinomial, kemudian menyisipkan nol diantara koefisien-koefisien trinomial pada bagian proses perkalian bersusun trinomial pangkat $\mathrm{n}-1$. Selanjutnya alternatif konstruksi koefisien trinomial dikonstruksi pada kerucut.
\end{abstract}

Kata kunci: Koefisien, Trinomial, Pascal.

\begin{abstract}
In the literature in general to determine the coefficient trinomial can easily be determined using the concept of combination and binomial coefficients, it is because the coefficient trinomial is closely related to the concept of binomial coefficients and combinations. For construction trinomial coefficients are usually constructed on Pascal pyramid whose origin is from Pascal's triangle. In this paper will be given an alternative determine the coefficient trinomial and alternative construction. Alternative award is a modification of the double decker multiplication. Stackable multiplication modification in question is to simply write down part of the process of multiplication decker on trinomial form, then insert a zero between the coefficients in the multiplication process trinomial trinomial decker rank $n-1$. Further construction alternative trinomial coefficients constructed in the cone.
\end{abstract}

Keywords: coefficient, trinomial, Pascal 


\section{Pendahuluan}

Kombinasi merupakan suatu materi yang telah diberikan sedari Sekolah Dasar hingga Perguruan Tinggi pada Jurusan Matematika dan Terapannya. Dengan kombinasi dapat ditentukan koefisien-koefisien binomial dan koefisien multinomial.

Kombinasi biasanya ditulis sebagai $\left(\begin{array}{l}n \\ r\end{array}\right)$. Bentuk $\left(\begin{array}{l}n \\ r\end{array}\right)$ dapat dipandang sebagai, banyaknya kombinasi dari $r$ unsur yang diambildari $n$ unsur dengan $n$ adalah bilangan bulat positif dan $r$ bilangan bulat $0 \leq r \leq n$ (Kenneth 2012). Sedangkan secara aljabar, dalam David (2009) dan John (2008) koefisien binomial merupakan koefisien suku $x^{n-r} y^{r}$ pada ekspansi $(x+y)^{n}$ untuk $n$ dan $r$ adalah bilangan cacah. Selanjutnya Munadi (2011) menerapkan rumus binomial pada perpangkatan bilangan bulat dua digit.

Segitiga Pascal merupakan koefisien-koefisien binomial yang disusun dalam bentuk segitiga. Selain membantu dalam ekspansi aljabar, aplikasi dari koefisien binomial banyak diterapkan dalam berbagai bidang seperti statistika dan kombinatorik.

James (1999) menuliskan bentuk umum trinomial sebagai.

$$
\begin{aligned}
& (a+b+c)^{p} \\
& =\sum_{m=0}^{p} \sum_{n=0}^{m}\left(\begin{array}{l}
p \\
m
\end{array}\right)\left(\begin{array}{c}
m \\
n
\end{array}\right) a^{p-m} b^{n} c^{m-n}
\end{aligned}
$$

Dengan menerapkan rumus koefisien multinomial (Miklos 2006) maka dapat diperoleh koefisien trinomial sebagai.

$$
\left(\begin{array}{c}
p \\
k_{1}, k_{2}, k_{3}
\end{array}\right)=\frac{p !}{k_{1} ! k_{2} ! k_{3} !}
$$

Koefisien trinomial adalah koefisien yang diperoleh dari ekspansi bentuk $(a+b+c)^{n}$. Michael (2011) melakukan perkalian dengan membalik posisi salah satu faktor $(x+y)^{n}$ untuk menentukan koefisien binomial, kemudian digeneralisasi untuk 3-Triangle dan 4-Triangle. Koefisien trinomial dapat dikonstruksi menjadi segitiga-segitiga yang mewakili koefisien $(a+b+c)^{n}$ (Martin, 2003, p.1-2). Selanjutnya koefisien trinomial $\quad(a+b+$ c) ${ }^{n}$ dikonstruksi (Stephen, 1969, p.417422) pada sebuah limas Pascals yang berlapis-lapis. Lapisan pada limas Pascal berbentuk segitiga yang di dalamnya berisi koefisien trinomial pangkat $n$. Metode lain untuk menentukan koefisien trinomial (Michael, 2011) adalah dengan mengalikan koefisien $(x+y)^{n}$ dengan segitiga Pascal binomial pangkat $n$.

Dari beberapa metode untuk menentukan koefisien trinomial yang telah dituliskan oleh Michael (2011), 
Martin (2003), dan Sthephen (1969), pada bagian selanjutnya akan diberikan alternatif menentukan koefisien trinomial dengan perkalian model tangga dan modifikasi perkalian bersusun serta konstruksi koefisien trinomial pada kerucut. Penelitian ini diharapkan dapat memperkaya metode dalam menentukan koefisien trinomial, sehingga dapat mempermudah dalam menentukan koefisien trinomial serta dapat digunakan dalam pembelajaran.

\section{Metode Penelitian}

Penelitian ini adalah studi literatur untuk mencari metode alternatif dalam menentukan koefisien trinomial. Studi literatur merupakan suatu teknik pengumpulan data dengan menghimpun dan menganalisis dokumen-dokumen, baik dokumen tertulis, gambar maupun elektronik. Berikut ini adalah tahapan yang dilakukan

1. Tahap persiapan. Pada tahap ini penulis mengumpulkan dan mempelajari buku-buku literatur yang berhubungan dengan koefisien trinomial, melakukan pencarian data melalui media internet, mengumpulkan teori-teori yang membahas koefisien trinomial

2. Tahap Pelaksanaan. Pada tahap ini penulis melakukan ekpsperimeneksperimen untuk menentukan koefisien trinomial dengan teori-teori yang sudah ada.

3. Tahap selanjutnya menyusun laporan penelitian.

\section{Hasil dan Pembahasan}

1. Menentukan Koefisien Trinomial Dengan Modifikasi Perkalian

\section{Bersusun}

Pada bagian ini, diberikan suatu metode dengan memodifikasi perkalian bersusun untuk koefisien trinomial. Untuk menentukan koefisien trinomial dengan modifikasi perkalian bersusun dapat dilakukan dengan langkah-langkah sebagai berikut:

1. Tulis $(a+b+c)^{n}=$ $(a+b+c)(a+b+c)^{n-1}$.

2. Susun koefisien $(a+b+c)^{n-1}$ sebanyak tiga kali dalam tiga baris. Baris pertama dituliskan dengan menyisipkan nol di antara koefisien pertama dan ke dua. Kemudian lompat dua koefisien dan sisipkan nol. Selanjutnya lompat tiga koefisien dan sisipkan nol dan seterusnya.

3. Pada baris kedua lakukan mengikuti aturan pada baris pertama dengan menuliskan koefisien pertama di bawah baris pertama menjorok satu posisi ke kiri. 
4. Pada baris ke tiga susun koefisienkoefsien $(a+b+c)^{n-1}$ di bawah baris kedua dengan ketentuan suku pertama diletakkan menjorok ke kiri satu posisi mengikuti baris kedua tanpa sisipan nol. Kemudian lakukan penjumlahan biasa.

Contoh 3 dan 4 merupakan penerapan dari modifikasi perkalian bersusun.

Contoh 3. Diberikan $(a+b+c)^{2}$, akan ditentukan koefisien $(a+b+c)^{2}$ dengan modifikasi perkalian bersusun. Pilih salah satu faktor $(a+b+c)^{2}$, yaitu $(a+b+c)$. Koefisien dari $(a+b+c)$ adalah 1, 1, 1. Tulis 1, 1, 1 sebanyak tiga kali dalam tiga baris dengan ketentuan sisipkan nol antara koefisien pertama dan kedua. Pada baris kedua, tulis koefisien pertama menjorok ke kiri satu posisi dari koefisien pertama pada baris pertama. Sisipkan nol antara koefisien pertama dan ke dua. Tulis 1, 1, 1 pada baris ketiga menjorok ke kiri satu posisi dibawah baris kedua tanpa menyisipkan nol. Lakukan penjumkahan biasa. Ilustrasinya dapat dilihat pada Gambar 1.

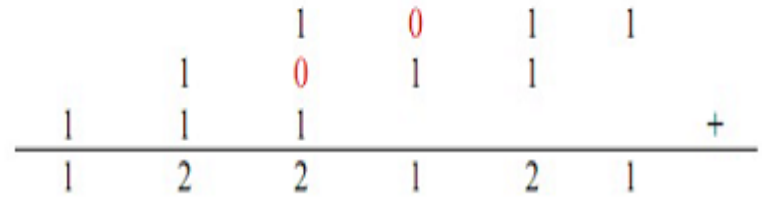

Gambar 1. Koefisien $(a+b+c)^{2}$ dengan modifikasi perkalian bersusun.

Jadi diperolah koefisien $(a+b+c)^{2}$ adalah 1, 2, 2, 1, 2, 1.

Contoh 4. Akan ditentukan koefisien $(a+b+c)^{3} \quad$ dan $\quad(a+b+c)^{4}$ menggunakan modifikasi perkalian bersusun. Dengan memanfaatkan koefisien $(a+b+c)^{2}$ pada contoh 3 . Koefisien $(a+b+c)^{3}$ diperoleh sebagai Gambar 2.

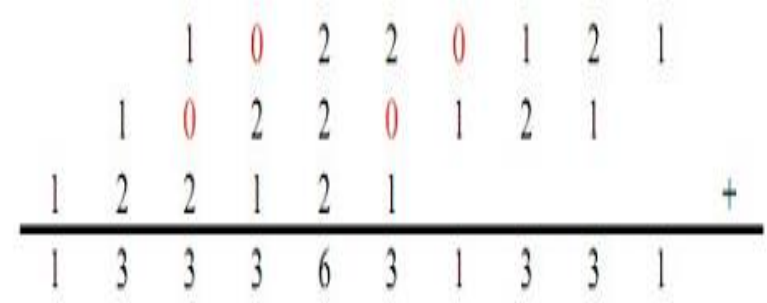

Gambar 2. Koefisien $(a+b+c)^{3}$ dengan modifikasi perkalian bersusun.

Dari Gambar 2 diperoleh koefisien $(a+b+c)^{3}$ adalah $1,3,3,3,6,3,1,3$, 1. Dengan menggunakan koefisien $(a+b+c)^{3}$ dapat pula ditentukan koefisien $\quad(a+b+c)^{4} \quad$ dengan modifikasi perkalian bersusun. Ilustrasinya dapat dilihat pada Gambar 3. 


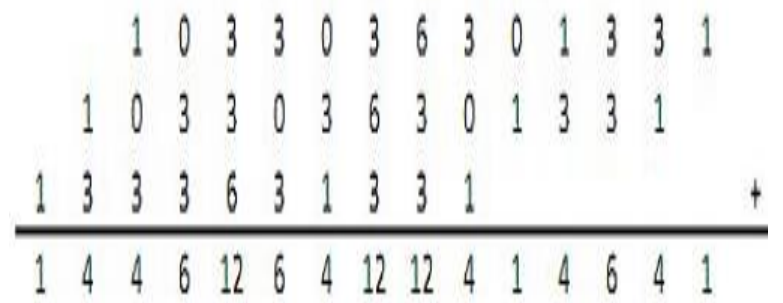

Gambar 3. Koefisien $(a+b+c)^{4}$ dengan modifikasi perkalian bersusun.

Dari Gambar 3 diperoleh koefisien $(a+b+c)^{4}$ adalah $1,4,4,6,12,6,4$, $12,12,4,1,4,6,4,1$.

\section{Konstruksi Koefisien Trinomial pada Kerucut}

Selain menggunakan segitiga dan limas Pascal, koefisien trinomial dapat dikonstruksi pada lingkaran dan kerucut. Berikut merupakan konstruksi koefisien trinomial dengan $n=$ $1,2,3,4,5$ pada lingkaran.

Penyusunan koefisien trinomial dimulai dengan pangkat $n=1$. Koefisien trinomial berpangkat 1 dapat disusun pada lingkaran dengan membagi sisi lingkaran menjadi tiga bagian sehingga membentuk juring lingkaran 120 derajat. Gambar 4 merupakan ilustrasi koefisien trinomial pangkat 1 pada lingkaran.

Koefisien trinomial pangkat 2 dapat disusun dengan menjumlahkan angka-angka yang berdekatan pada sisi lingkaran trinomial pangkat 1 sehingga diperoleh 1, 2, 1, 2, 1, 2 dan digambarkan pada Gambar 5. Untuk koefisien trinomial pangkat 3, angka disisinya didapat dari jumlah 2 angka yang berdekatan pada sisi lingkaran trinomial pangkat 2, kemudian menjumlahkan 3 angka yang berdekatan pada lingkaran trinomial pangkat 2 kecuali angka 1 yaitu $2+2+2=6$, kemudian tulis di dalam lingkaran. Gambarnya dapat dilihat pada Gambar 6.

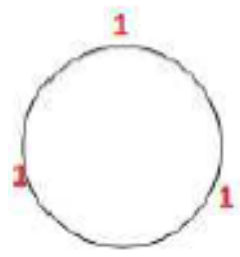

Gambar 4. Koefisien trinomial pangkat 1 pada lingkaran.

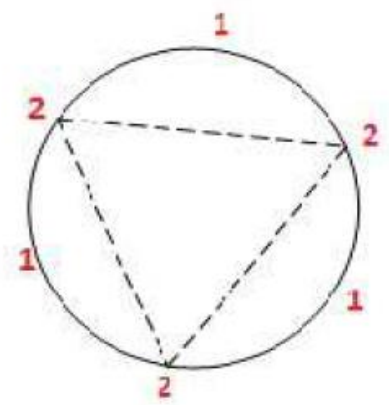

Gambar 5. Koefisien trinomial pangkat 2 pada lingkaran.

Untuk koefisien trinomial pangkat 4, angka disisinya didapat dari jumlah 2 angka yang berdekatan pada sisi lingkaran trinomial pangkat 3 , kemudian menjumlahkan 3 angka yang berdekatan pada lingkaran trinomial pangkat 3 kecuali angka 1 yaitu $3+3+6=12$, kemudian tulis di dalam lingkaran. Gambarnya disajikan pada Gambar 7. Untuk koefisien trinomial pangkat 5 
diterapkan langkah-langkah seperti menyusun koefisien pangkat 1, 2, 3, dan

4. Ilustrasinya dapat dilihat sebagaimana Gambar 8.

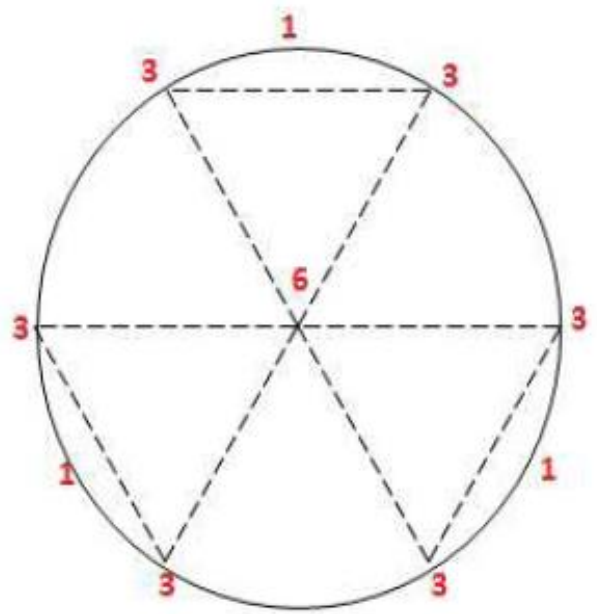

Gambar 6. Koefisien trinomial pangkat 3 pada lingkaran.

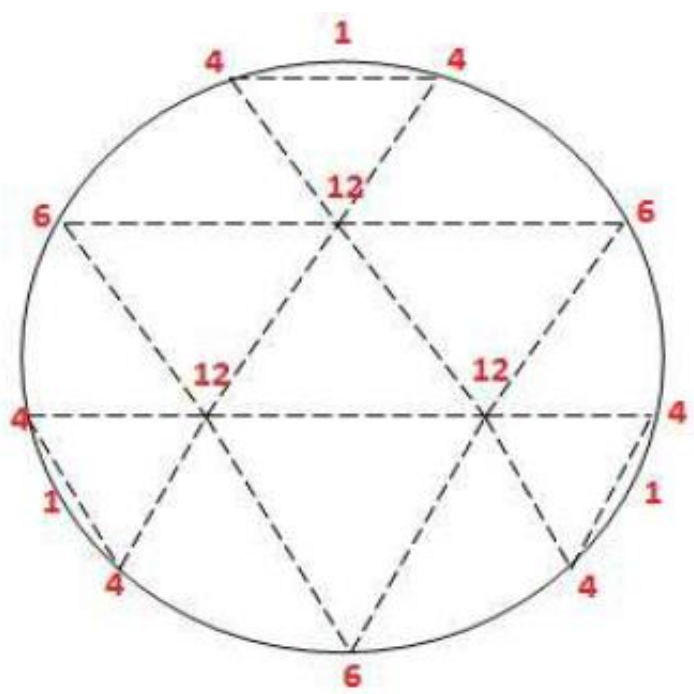

Gambar 7. Koefisien trinomial pangkat 4 pada lingkaran.

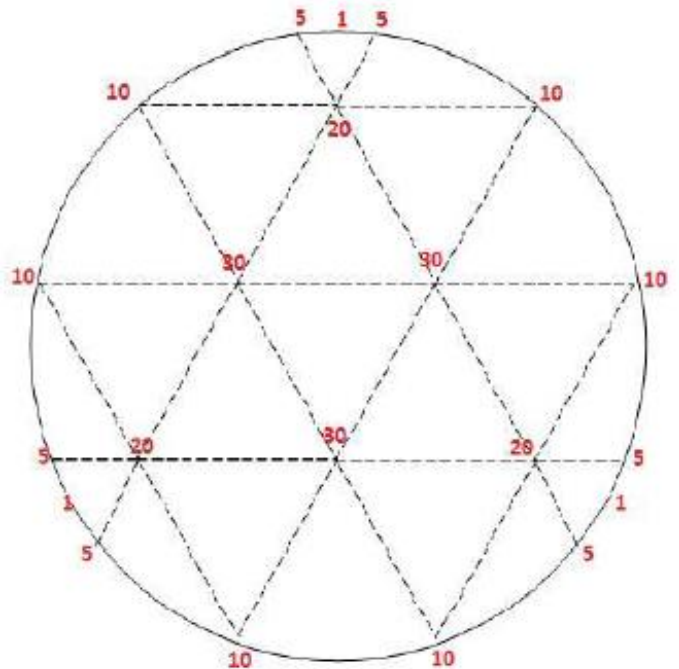

Gambar 8. Koefisien trinomial pangkat 5 pada lingkaran.

\section{Lingkaran-lingkaran}

yang

memuat koefisien-koefisien trinomial dapat dirangkum sebagaimana Gambar 9.

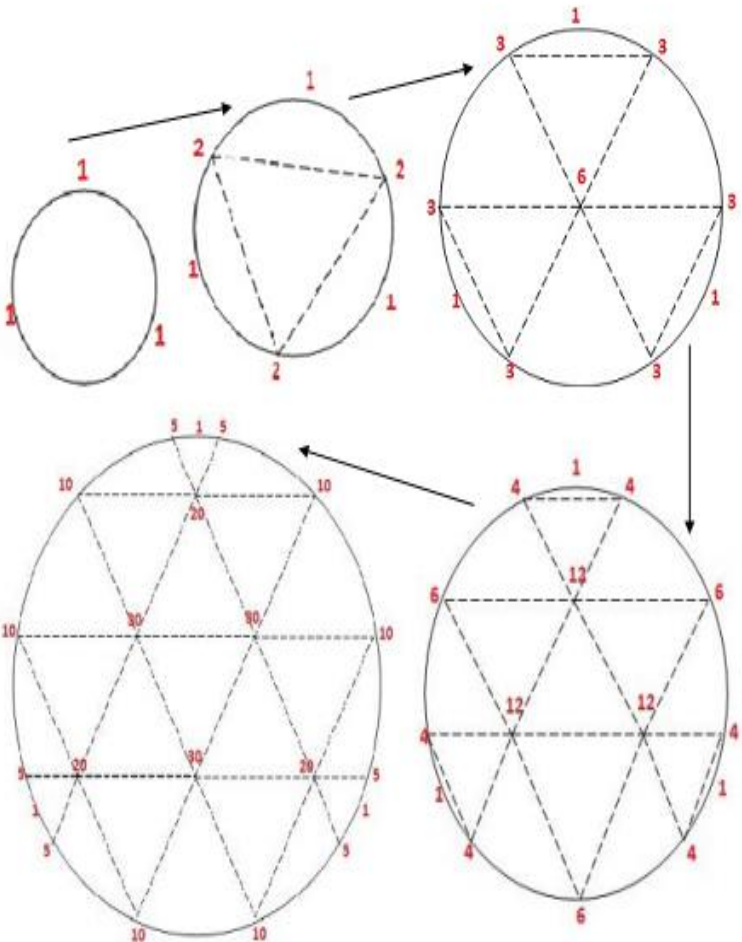

Gambar 9. Koefisien-koefisien trinomial pada lingkaran. 
Memperhatikan perilaku yang ditunjukkan oleh lingkaran yang memuat koefisien trinomial, didapat bahwa pada sisi-sisi lingkaran merupakan koefisien binomial barisan $n$, pada bagian dalam lingkaran merupakan jumlah dari tiga koefisien yang berdekatan pada trinomial pangkat $n-1$. Jika lingkaran- lingkaran trinomial disusun secara berurutan, akan terbentuk sebuah kerucut yang berisi koefisien-koefisien trinomial. Kerucut tersebut terdiri dari lapisan- lapisan yang memuat koefisien trinomial pangkat $\mathrm{n}$. Konstruksi kerucut ini merupakan bentuk atau cara lain menyajikan koefisien trinomial selain dengan Limas Pascal. Kerucut yang memuat koefisien trinomial dapat dilihat pada Gambar 10.

Pada sisi lingkaran yang memuat koefisien trinomial merupakan koefisien binomial. Angka-angka pada setiap lingkaran merupakan jumlah dari tiga angka yang berdekatan di lingkaran sebelumnya. Banyaknya koefisien pada setiap lingkaran adalah $3,6,10,15,21, \ldots$ atau $\frac{(n+1)(n+2)}{2}$. Jumlah dari angka-angka pada setiap lingkaran adalah $3^{n}$. Dengan menyusun lingkaran-lingkaran yang memuat koefisien trinomial maka akan terbentuk kerucut yang memuat koefisien trinomial seperti Gambar 10.

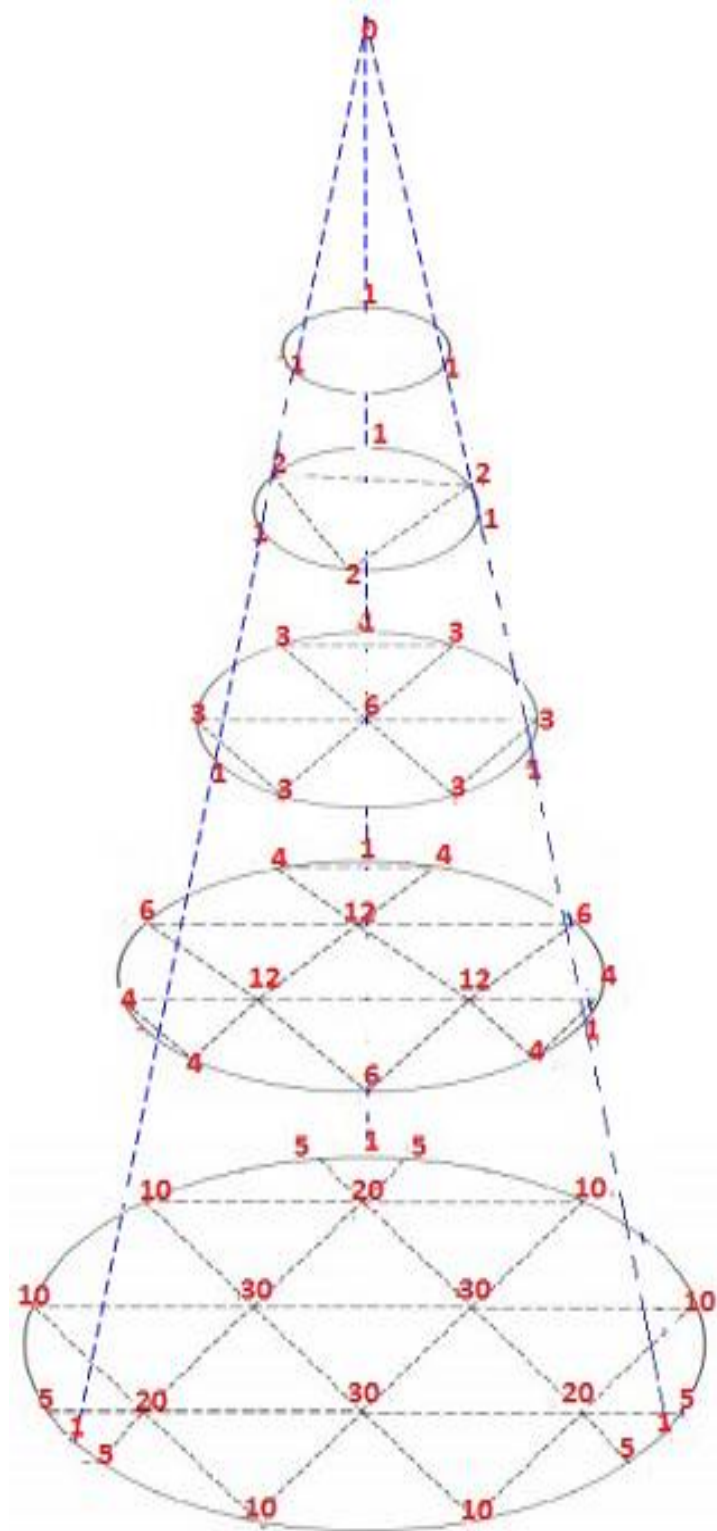

Gambar 10. Kerucut yang memuat koefisien trinomial.

\section{Kesimpulan}

Pada tulisan ini telah dibahas alternatif menentukan koefisien trinomial dan konstruksinya. Alternatif yang berikan yaitu dengan metode modifikasi perkalian bersusun. Modifikasi perkalian bersusun dilakukan dengan menyisipkan nol diantara koefisien-koefisien trinomial pangkat $n-1$. Selanjutnya koefisien trinomial dikonstruksi pada kerucut yang 
berasal dari lingkaran yang memuat koefisien trinomial.

Penelitian ini dapat dilanjutkan dengan mencari alternatif-alternatif lain untuk menentukan koefisien trinomial atau koefisien multinomial yang lain.

\section{Ucapan Terima Kasih}

Ucapan terima kasih penulis ucapkan kepada dosen pembimbing tesis yang telah memberikan masukan dan arahan sehingga artikel ini dapat diselesaikan. Ucapan terima kasih juga penulis tujukan kepada panitia Seminar Pendidikan Matematika Uninersitas Ahmad Dahlan tahun 2015 yang memilih artikel ini untuk diterbitkan pada Jurnal AdMathEdu.

\section{Pustaka}

David. M. B., 2011. Elementary Number Theory. Seventh Editions. McGraw- Hill, New York.

James. C dan Thomas. J. O., 1999, The Trinomial Triangle. The College Mathematics Journal, 30(2), 141142.

Jhon. E. B., dan Ann Baker., 2013, Pascal Pyramids: a mathematical exploration using spreadsheets. eJSiE, 6, 1-7.

John. M. H., Jeffry. L. H., and Michael. J. M., 2008, Combinatorics and Graph Theory. Second Edition. New York, Springer.

Kenneth H. R., 2012, Discrete Mathematies and Its Applications. Seventh Editions. McGraw-Hill, New York.
Martin. E. H., 2003, Pascal Pyramids, Pascal Hyper-Pyramids and a Bilateral Multinomial Theorem, arxiv. Org 1, 12. arXiv. Org. Web. 5 April 2015

Michael, A. K., 2011, Generalization's of Pascal's Triangle: A Construction Based Approach, Thesis, Department of Mathematical Sciences, College of Sciences The Graduate College, University of Nevada, Las Vegas,.

Miklos Bona., 2006, A Walk Trugh Combinatorics: an antroduction to enumeration and graph theory, Second Editions, World Scientific Publishing, USA.

Munadi, 2011, Aplikasi Rumus Binomial Newton pada Pemangkatan Bilangan Bulat Dua Digit. Prosiding Matematika dan Pendidikan Karakter dalam Pembelajaran A-13(2011), 126- 129, FMIPA UNY, Yogyakarta.

Stephen Mueller., 1969, Recursions Associated With Pascal's Pyramid. University Oklahoma. PI MU EPSILON, Journal, 4(10), 417-422. 